Research Article

\title{
Assessment on Association of Epidemiological Factors with Urinary tract infection among
} Adults of South India

\author{
Satish Kumar B P1, Anwitha Johns2², Lavanya P R², Lipika Das², Meghana A2 \\ ${ }^{1}$ Associate Professor, Department of Pharmacy Practice, Sri Adichunchanagiri College of Pharmacy, Adichunchanagiri University, \\ Mandya, Karnataka, India. \\ 2Pharm D Interns, Department of Pharmacy Practice, Sri Adichunchanagiri College of Pharmacy, Adichunchanagiri University, Mandya, \\ Karnataka, India. \\ *Corresponding author's E-mail: anvithajhons@gmail.com
}

Received: 09-01-2021; Revised: 18-02-2021; Accepted: 27-02-2021; Published on: 20-03-2021.

\begin{abstract}
Urinary tract infections (UTIs) are equally shared in both community and hospital setting. Good knowledge of epidemiological data is very necessary for the initial appropriate empirical treatment of UTI. The main aim is to find the associations of epidemiological data with the UTI. To assess the association of epidemiological factors with urinary tract infection, a questionnaire regarding sociodemographic details and basic information of UTI was formulated. The minimum of 412 sample size was measured using Raosoft software. Data were relocated into Microsoft Excel spreadsheets and confirmed for its accuracy. In this study age, gender, marital status and education level were considered as epidemiological factors. The prevalence of urinary tract infection has equally distributed in all the age groups. About $60.1 \%$ of the female and $57.3 \%$ of the male participants are frequently suffering from the UTI. $82.7 \%$ of the married and $47.6 \%$ of the unmarried population are undergoing the burden of the disease. To conclude, the study strongly tells there is no association of the UTI with age but has a strong association with the gender, marital status and also the education level. The study also supports that most of the population have antibiotic-resistance UTI.
\end{abstract}

Keywords: Urinary tract infection, epidemiological factors, South India, Association.

QUICK RESPONSE CODE $\rightarrow$

DOI:

10.47583/ijpsrr.2021.v67i01.005

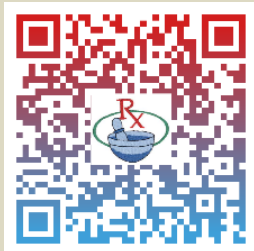

DOI link: $\underline{\text { http://dx.doi.org/10.47583/ijpsrr.2021.v67i01.005 }}$

\section{INTRODUCTION}

U rinary tract infection is a broad term which describes an infection that involves any part of the urinary tract like ureters, kidney, bladder and urethra. The urinary tract is divided into the lower tract(cystitis) like bladder and urethra and upper tracts like kidneys and ureters. ${ }^{1}$

Numerous risk factors are being associated with cystitis which includes gender, sexual activity, prior UTI, vaginal infection, obesity and genetic susceptibility. ${ }^{2}$ Urinary tract infection can also stratify as 2 types which as follows like HAUTI (healthcare-associated urinary tract infection) and CAUTI community-associated urinary tract infection). The main epidemiological factors that affect the urinary tract infection, resistance rate and causative agents are like sex, age group, geographical area and surroundings. In this present situation of high resistance rates towards antibiotics, perceiving the information of epidemiology becomes more important than before. Maximum times, men will be affected with CAUTI which is complicated with the cause of infection. ${ }^{3}$
In each age group, than in men, women are having a higher incidence rate of UTI, in $12.6 \%$ of annual incidence only $3 \%$ is men. At least by the age group of 32 , half of the women have a history of UTI at least once but in men, one-fifth of them have experienced UTI in their seventies. The incidence is higher among women which are attributed to the differences in the anatomy because in women periurethral spaces are moist and distance is shorter between urethral openings and bladder and between urethral openings and anus. ${ }^{4}$

Mainly E Coli transmits in sexual activity from a male sex partner, in sets which are randomly assigned to use a lubricated non-spermicide condom or no condom, colonization with the vagina, E Coli increases the risk of UTI and proportionately high in the group of not using condoms than in group using a lubricated non-spermicide condom. ${ }^{5}$

\section{MATERIAL AND METHODS}

\section{Development and content of the Questionnaire}

To assess the association of epidemiological factors with urinary tract infection, an anonymous questionnaire with 15 questions regarding sociodemographic details and basic information for UTI was formulated using Google forms. The questionnaire was designed in cooperation with an expert in the field. Simple random sampling was made for selecting the participants. The link to the survey was shared with the intended participants through email and WhatsApp. The questionnaire was mainly focusing on the 
participant's experience in UTI. To finish, it was asked if the participant had any question on the UTI. The questionnaire was kept aware for four weeks, and the people were reminded to fill it up.

Study Design: Observational cohort prospective study.

\section{Sample size}

The minimum of 412 sample size was measured using Raosoft software at a $95 \%$ confidence interval with a $5 \%$ margin of error and with the response rate of $70 \%$.

\section{Inclusion Criteria}

Adults of South India (above the age of 18)

\section{Exclusion criteria}

People who were not interested to enroll in the study

Study duration: November 2020 to January 2021.

\section{Statistical analysis}

Data were relocated into Microsoft Excel spreadsheets and confirmed for its accuracy. Obtained data were analyzed using the IBM SPSS statistics software for windows, version 22 (Armonk, NY, USA). Numbers and percentages were assessed in categorical and nominal data. Epidemiological factors used in the study included age, sex, education level and marital status. Besides, the Chi-square $(\chi 2)$ test was used for the comparison between each epidemiological factors and the prevalence of urinary tract infection. $\mathrm{P}<$ 0.05 was set as the level of significance.

\section{RESULTS}

\section{Epidemiological factors}

In this study age, gender, marital status and education level were considered as epidemiological factors. A total of 412 respondents registered in the study. Of this, 133 (32.3\%) were males and 279 (67.7\%) were females. The mean age of the subjects was $24.05 \pm 8.1$ years, where more than half of the participants $(66.7 \%)$ belongs to the age group 18-25 years and more than half of the participants (66.3\%) were single. Graduated (31.6\%) and undergraduate $(52.7 \%)$ were the majority of participants. All the epidemiological factors are detailed in (Table 1).

Table 1: Epidemiological factors of the participants ( $N=412)$

\begin{tabular}{|lll|}
\hline Variables & Participants (N) & Percentage (\%) \\
\hline Age in years & 275 & 66.7 \\
\hline $18-25$ & 85 & 20.6 \\
\hline $26-35$ & 38 & 9.2 \\
\hline $36-45$ & 12 & 2.9 \\
\hline $46-55$ & 02 & 0.5 \\
\hline $56-65$ & & \\
\hline Gender & 279 & 67.7 \\
\hline Female & 133 & 32.3 \\
\hline Male & & \\
\hline Marital status & 139 & 33.7 \\
\hline Married & 273 & 66.3 \\
\hline Unmarried & & \\
\hline Education & 28 & 6.8 \\
\hline Illiterate & 12 & 2.9 \\
\hline Primary education & 25 & 6.1 \\
\hline Secondary education & 217 & 52.7 \\
\hline Degree & 130 & \\
\hline Any higher education & & \\
\hline
\end{tabular}

\section{Information to correlate with epidemiological factors}

In the conducted survey, more than half of the participants have heard about urinary tract infection. About $54.6 \%$ of the subjects are frequently experiencing urinary tract infection in which hospital-acquired urinary tract infection is in the leading position. A good number of population had undergone antibiotic treatments in which $60 \%$ of the population developed antibiotic resistance which lead to treatment failure (Table 2) 
Table 2: General information of Participants on UTI ( $N=412)$.

\begin{tabular}{|c|c|c|}
\hline Questions & Yes & No \\
\hline $\begin{array}{l}\text { 1. Have you ever been affected by } \\
\text { urinary tract infection (UTI)?? }\end{array}$ & $\begin{array}{r}250 \\
(60.7 \%)\end{array}$ & $\begin{array}{r}162 \\
(39.3 \%)\end{array}$ \\
\hline $\begin{array}{l}\text { 2. Are you frequently experiencing } \\
\text { urinary tract infection? }\end{array}$ & $\begin{array}{c}225 \\
(54.6 \%)\end{array}$ & $\begin{array}{r}187 \\
(45.4 \%)\end{array}$ \\
\hline $\begin{array}{l}\text { 3.Have you experienced UTI within } \\
\text { the last } 1 \text { year? }\end{array}$ & $\begin{array}{c}232 \\
(56.3 \%)\end{array}$ & $\begin{array}{c}180 \\
(43.7 \%)\end{array}$ \\
\hline \multicolumn{3}{|l|}{ 4. Which type of UTI you were/are affected with? } \\
\hline Community-acquired UTI & $\begin{array}{c}68 \\
(16.5 \%)\end{array}$ & $\begin{array}{c}344 \\
(83.4 \%)\end{array}$ \\
\hline Hospital-acquired UTI & $\begin{array}{c}182 \\
(44.2 \%)\end{array}$ & $\begin{array}{r}230 \\
(55.8 \%)\end{array}$ \\
\hline 5. Did you take antibiotics to treat UTI? & $\begin{array}{r}248 \\
(60.2 \%)\end{array}$ & $\begin{array}{c}162 \\
(39.8 \%)\end{array}$ \\
\hline 6. Did antibiotics help you relieving from UTI? & $\begin{array}{l}165 \\
(40 \%)\end{array}$ & $\begin{array}{r}247 \\
(60 \%)\end{array}$ \\
\hline
\end{tabular}

\section{Association of epidemiological factors with UTI}

Age (in years)

The undertaken survey reveals less UTI burden in the 1825 age group. The prevalence of urinary tract infection has equally distributed in all other age groups i.e $76.5 \%$ in 26 $35,78.9 \%$ in $36-45$ and $83,3 \%$ in $46-55$ (Fig 1). Our study shows UTI is not much dependent on the epidemiological factor, age.

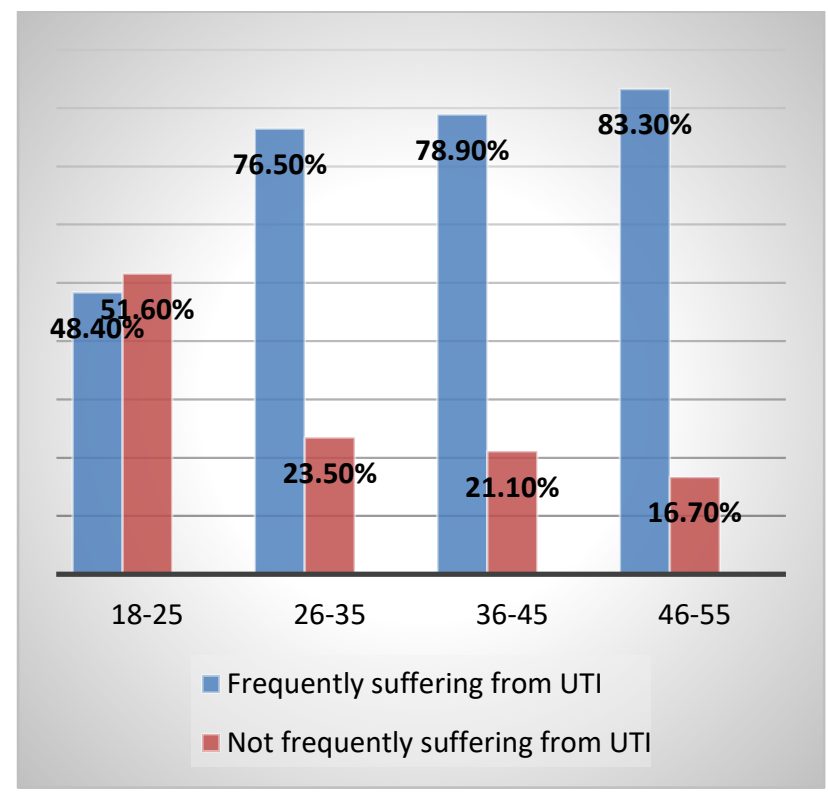

Figure 1: Association between age (in years) and UTI

\section{Gender}

The conducted survey confirms the increased burden of urinary tract infection in females but also reveals that male burden is approximately reaching the female. About $60.1 \%$ of the female participants are frequently suffering from the UTI and $57.3 \%$ of the male participants are recurrently experiencing the UTI (Fig 2). UTI is dependent on the epidemiological factor, gender.

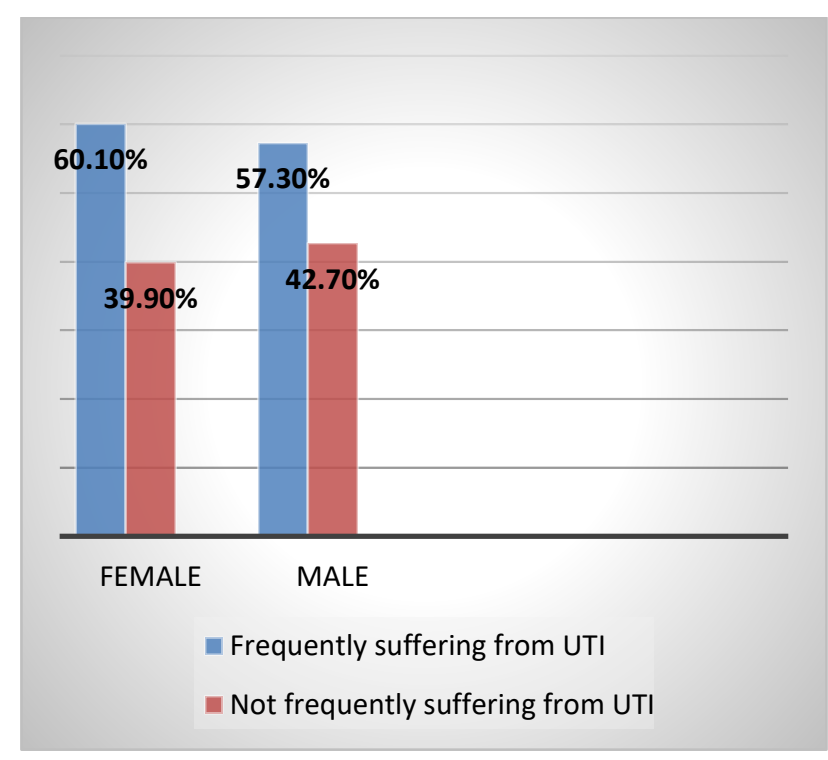

Figure 2: Association between gender and UTI

\section{Marital status}

The survey also confirms the increased burden of UTI in the married population than the unmarried. $82.7 \%$ of the married population are recurrent to the UTI whereas only $47.6 \%$ of unmarried participants are undergoing the burden of the disease (Fig 3). According to our study, UTI is dependent on the epidemiological factor, marital status. 


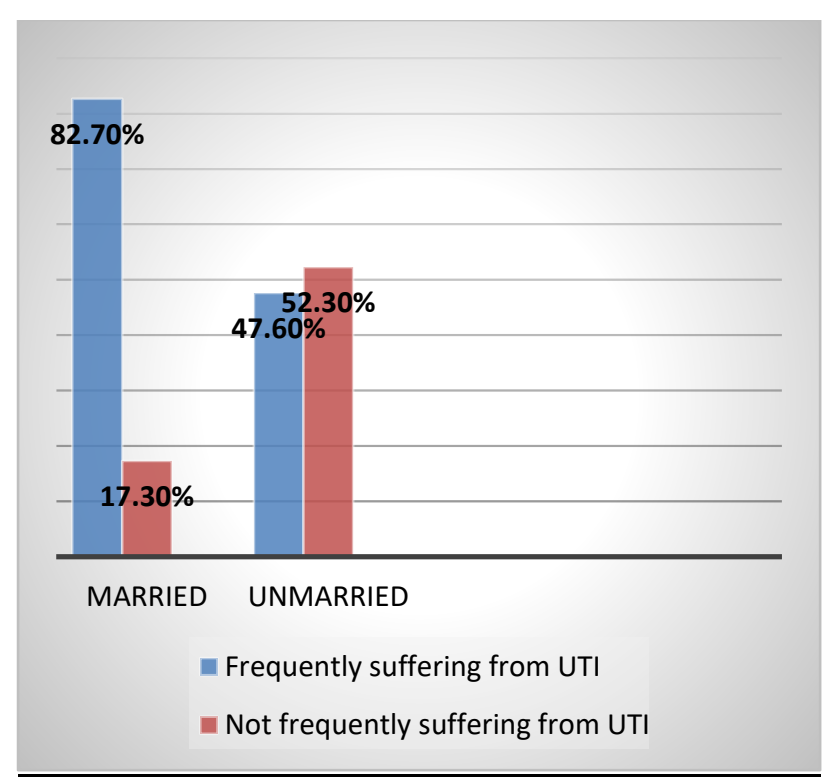

Figure 3: Association between marital status and UTI

\section{Education level}

The study has a good correlation between the incidence of UTI and the education level of the participants. As expected, the study shows less incidence in the highly educated participants because of the knowledge of preventive measures however an increased incidence of UTI is seen in illiterates. $89.3 \%$ of the illiterate population is suffering from recurrent UTI and only $22 \%$ of the higher educated population is suffering from the recurrent UTI (Fig 4). According to our study, UTI is completely dependent on the epidemiological factor, education level.

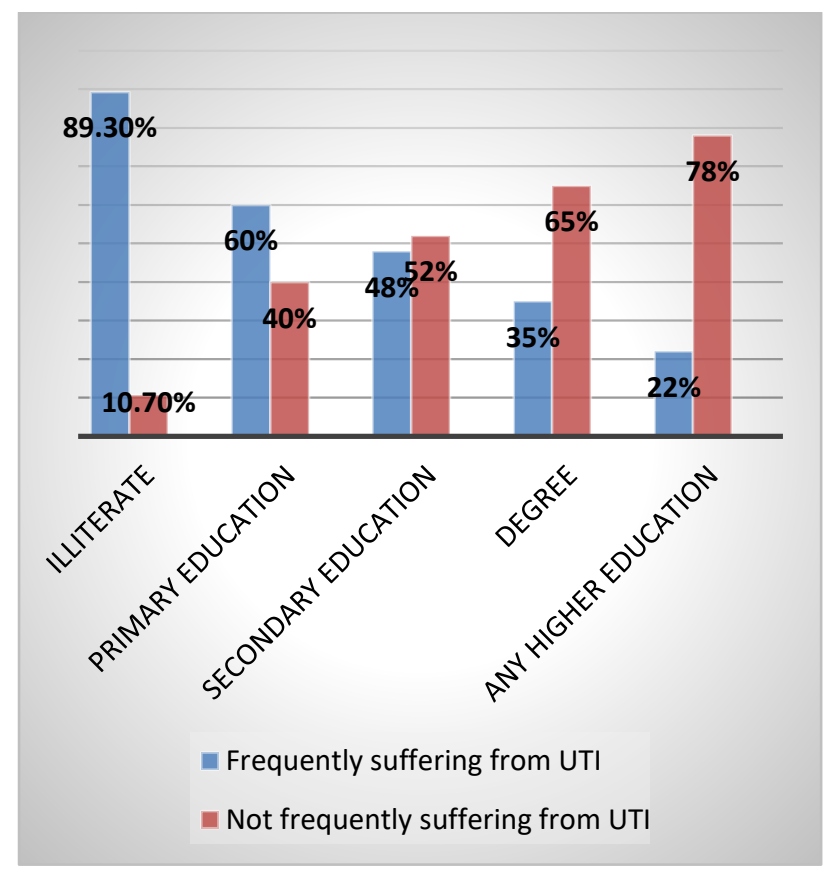

Figure 4: Association between education level and UTI

\section{DISCUSSION}

Urinary tract infections (UTIs) are equally shared in both community and hospital setting. Good knowledge of epidemiological data is very necessary for the initial appropriate empirical treatment of UTI. Knowing the appropriate associations of epidemiological data will help in determining the exact cause of the disease as well as risk factors, which lead to plan correct therapy thereby reduces the incidence of the disease.

In this study, we considered the four main epidemiological factors, age, gender, marital status and education level. Our study showed an association of UTI with gender, marital status and also education level. But study confirmed no association of the disease with the age. Females married and illiterate showed more incidence of urinary tract infection than males, unmarried and educated respectively.

Stefano Salvatore, Silvia Salvatore, Elena Cattoni et.al, conducted a complete literature review of published investigational and clinical studies of UTI at the University of Insubria electronic library (SFX Bicocca-Insubria) with cross-search of seven dissimilar medical databases. The prevalence of UTI is greater in women than in men. About $81 \%$ of UTI happens in women, with a peak between 16 and 35 years. Approximately $27 \%$ of women with the first episode of UTI show a recurrence within 6 months, and $48 \%$ within the first year. ${ }^{6}$

Delia Scholes, Thomas M. Hooton, Pacita L et.al, conducted a case-control study was in 2 populations i.e university women and health maintenance organization enrollees to define host factors associated with an increased risk of recurrent urinary tract infection (RUTI). The study concluded risk factors for such urinary tract infection include sexual activity, spermicide-based contraception, and a history of previous UTIs. They confirmed that married women are more at greater risk for UTI. ${ }^{7}$

Satish Kumar B. P, Mohammed Zuber, Anwitha Johns, Vinod Kumar $\mathrm{V}$ conducted a descriptive study using a restructured and pretested questionnaire to assess the knowledge and attitude of the rural people. Descriptive statistics were used to represent the study characteristics. The study tells that there is a significant association between the literacy level of participants and knowledge score. They also confirmed that the education level is an important factor in which the incidence of particular diseases lies. ${ }^{8}$

\section{Limitations}

Age, gender, marital status and education level were not equally distributed among the participants.

\section{CONCLUSIONS}

Urinary tract infection is one of the serious approaching burdens of the country. The study confirms the association of the basic epidemiological factors with the urinary tract infection to support the reduction of the incidence of the disease. To conclude, the study strongly tells there is no association of the UTI with age but has a strong association with the gender, marital status and also the education level. In other words, females, married and illiterates (who do not know preventive measures of UTI) are the risk 
factors for urinary tract infection. The study also supports that most of the population have antibiotic-resistance UTI.

\section{REFERENCES}

1. Tan CW, Chlebicki MP. Urinary tract infections in adults. Singapore medical journal. 2016 Sep; 57(9): 485.

2. Flores-Mireles AL, Walker JN, Caparon M, Hultgren SJ. Urinary tract infections: epidemiology, mechanisms of infection and treatment options. Nature reviews microbiology. 2015 May; 13(5): 269-84.

3. Tandogdua Z, Florian ME. Wagenlehner. Global epidemiology of urinary tract infections. Thomson [Internet]. 2016; 29(1): 7.

4. Foxman B, Brown P. Epidemiology of urinary tract infections: transmission and risk factors, incidence, and costs. Infectious Disease Clinics. 2003 Jun 1; 17(2): 227-41.

5. Eschenbach DA, Patton DL, Hooton TM, Meier AS, Stapleton A, Aura J, Agnew K. Effects of vaginal intercourse with and without a condom on vaginal flora and vaginal epithelium.
The Journal of infectious diseases. 2001 Mar 15; 183(6): 9138.

6. Salvatore $S$, Salvatore $S$, Cattoni $E$, Siesto $G$, Serati $M$, Sorice $P$, et al. Urinary tract infections in women. Vol. 156, European Journal of Obstetrics and Gynecology and Reproductive Biology. Elsevier Ireland Ltd; 2011; p. 131-6.

7. Scholes D, Hooton TM, Roberts PL, Stapleton AE, Gupta K, Stamm WE. Risk Factors for Recurrent Urinary Tract Infection in Young Women. J Infect Dis [Internet]. 2000 Oct 1 [cited 2021 Jan 12]; 182(4): 1177-82. Available from: https://academic.oup.com/jid/articlelookup/doi/10.1086/315827

8. Kumar S, Zuber M, Johns A, Kumar V. Knowledge and attitude of rural community towards the respiratory diseases. Int J Community Med Public Heal Satish KBP al Int J Community Med Public Heal [Internet]. 2020 Sep 25 [cited 2021 Jan 12]; 7(10): 4071-5. Available from: http://www.ijcmph.com

Source of Support: None declared.

Conflict of Interest: None declared.

For any question relates to this article, please reach us at: editor@globalresearchonline.net New manuscripts for publication can be submitted at: submit@globalresearchonline.net and submit_ijpsrr@rediffmail.com 